Revista Eletrônica de Direito Processual - REDP.

Rio de Janeiro. Ano 13. Volume 20. Número 1. Janeiro a Abril de 2019

Periódico Quadrimestral da Pós-Graduação Stricto Sensu em Direito Processual da UERJ

Patrono: José Carlos Barbosa Moreira (in mem.). ISSN 1982-7636. pp. 131-153

www.redp.uerj.br

\title{
JURISDIÇÃO BRASILEIRA NOS PROCESSOS COLETIVOS \\ TRANSNACIONAIS: O QUE PODEMOS APRENDER COM AS DISCUSSÕES \\ ENFRENTADAS NO CONTEXTO EUROPEU? ${ }^{1}$
}

\section{BRAZILIAN JURISDICTION IN TRANSNATIONAL COLLECTIVE REDRESS: WHAT CAN WE LEARN FROM THE DISCUSSIONS FACED IN A EUROPEAN CONTEXT?}

Daniela Bermudes Lino

Mestranda em Direito Processual pela Universidade Federal do Espírito Santo (UFES). Pesquisadora vinculada ao Grupo de Pesquisa Fundamentos do Processo Civil Contemporâneo - FPCC (UFES). Monitora da disciplina Processo Coletivo e Procedimentos Especiais (Processo Civil VI) no curso de graduação em Direito da UFES. Assessora no Ministério Público do Estado do Espírito Santo. Vitória/ES. E-mail: danielabermudes1@gmail.com

RESUMO: O presente artigo objetiva a analisar o tema da jurisdição brasileira nos processos coletivos transnacionais. Para isso, realiza-se uma abordagem de conceitos centrais ao assunto e, posteriormente, examina-se algumas discussões que já estão sendo enfrentadas na União Europeia quanto à competência internacional em casos coletivos transnacionais, especialmente sob a ótica do instrumento Bruxelas I bis (Regulamento 1215/2012). Ao final, se expõe o tema da jurisdição brasileira em processos coletivos transnacionais em cotejo com as discussões levantadas acerca do contexto europeu e com foco em uma leitura adequada do Código de Processo Civil de 2015.

PALAVRAS-CHAVE: Jurisdição brasileira; Processo coletivo transnacional; União Europeia.

\footnotetext{
${ }^{1}$ Artigo recebido em 15/07/2018 e aprovado em 09/10/2018.
} 
Revista Eletrônica de Direito Processual - REDP.

Rio de Janeiro. Ano 13. Volume 20. Número 1. Janeiro a Abril de 2019

Periódico Quadrimestral da Pós-Graduação Stricto Sensu em Direito Processual da UERJ

Patrono: José Carlos Barbosa Moreira (in mem.). ISSN 1982-7636. pp. 131-153

www.redp.uerj.br

\begin{abstract}
The present article's objective is to analyse the Brazilian jurisdiction in transnational collective redress. To do this, an approach to central concepts to the subject is made and, subsequently, it is examines some of the discussions that are already being faced in the European Union regarding the jurisdiction in transnational collective cases, especially from the perspective of the Brussels I bis (Regulation 1215/2012). At the end, if exposes the issue of Brazilian jurisdiction in transnational collective redress in comparing with the discussions raised about the European context and with a focus on a proper reading of the Code of Civil Procedure of 2015.
\end{abstract}

KEYWORDS: Brazilian jurisdiction; Transnational collective redress; European Union.

SUMÁRIO: 1. Introdução; 2. Jurisdição, Competência internacional e Processo Coletivo Transnacional: Extraterritorialidade física ou jurídica; 3.União Europeia e Competência internacional para litígios coletivos transnacionais; 4. Jurisdição brasileira para processos coletivos transnacionais: O que o Brasil pode aprender com a União Europeia? 5. Considerações finais; 6. Referências bibliográficas.

\title{
1 Introdução
}

$\mathrm{O}$ fenômeno da globalização marcou o século $\mathrm{XX}$ e vem se intensificando de maneira crescente na sociedade mundial. A relação entre pessoas de diferentes países e, principalmente, as atividades das empresas transnacionais no mercado global acabaram por dar lugar ao que se denomina de casos multinacionais ou transnacionais, isto é, casos que se vinculam a mais de um sistema jurídico, pela existência de controvérsia com um ou mais elementos de estraneidade.

Em concomitância com esse processo de globalização, surgiram, também no século $\mathrm{XX}$, em decorrência das atividades das empresas multinacionais, transformações sociais, econômicas e tecnológicas que marcaram um processo de transição da predominância de relações jurídicas individualizadas para um conjunto crescente de situações jurídicas coletivas, refletindo o surgimento dos litígios de massa. Danos consumeristas, danos ambientais, violações aos direitos humanos, entre outros, são exemplos de consequências da sociedade industrial capitalista e das atividades empresariais.

O convívio entre os fenômenos da globalização e do crescimento das situações jurídicas coletivas fez emergir, no âmbito do Processo Civil Internacional Contemporâneo, 
Revista Eletrônica de Direito Processual - REDP.

Rio de Janeiro. Ano 13. Volume 20. Número 1. Janeiro a Abril de 2019

Periódico Quadrimestral da Pós-Graduação Stricto Sensu em Direito Processual da UERJ

Patrono: José Carlos Barbosa Moreira (in mem.). ISSN 1982-7636. pp. 131-153

www.redp.uerj.br

novos problemas, ligados à tutela coletiva transnacional. São problemas que surgem pela potencial extraterritorialidade física ou mesmo jurídica das situações coletivas, que dificultam a definição da jurisdição.

Esse complexo desafio de encarar litígios coletivos transnacionais já vem sendo experimentado em outros locais do mundo, como Estados Unidos, Canadá, União Europeia, dando origem a tutelas que têm sido denominadas de global class actions, crossborder collective redress, acciones colectivas transfronterizas, todas referentes a espécies de mecanismos coletivos. O desafio é complexo, porque a territorialidade dos Estados nacionais, reiteradamente, conflita com a extraterritorialidade das situações coletivas, resultando na formação de um quadro em que os sistemas jurídicos, muitas vezes, não oferecem respostas à realidade social e econômica contemporânea. A definição da jurisdição ou competência internacional em litígios coletivos transnacionais é o ponto principal desse desafio.

No Brasil, embora exista um sistema de tutela coletiva reconhecido, em que se identifica a definição da competência como um dos aspectos mais relevantes, ainda não foi dedicada mais atenção ao tema da extensão e limites da jurisdição brasileira para processos coletivos transnacionais, a partir da análise da aplicabilidade das regras de jurisdição nacional previstas do art.21 ao 25 do Código de Processo Civil de 2015.

O presente artigo pretende justamente abordar o tema da jurisdição brasileira diante de processos coletivos transnacionais. Essa abordagem será feita a partir das discussões travadas no contexto do sistema comunitário europeu, que embora pouco tenha desenvolvido em termos de processo coletivo, muito desenvolveu em termos de jurisdição, cujo modelo, pautado em hipóteses abstratamente previstas, foi em parte adotado pelo CPC. Para essa abordagem, esse artigo estrutura-se em três partes: A primeira trata de conceitos centrais à temática da jurisdição em processos coletivos transnacionais; A segunda desenvolve as discussões já levantadas sobre competência jurídica internacional e litígios coletivos na União Europeia, especialmente, sob a ótica do Bruxelas I bis; Por fim, a terceira trava uma análise da jurisdição brasileira nos processos coletivos transnacionais, em cotejo com as discussões levantadas acerca do contexto europeu e com foco em uma leitura adequada do Código de Processo Civil de 2015.

2 Jurisdição, Competência internacional e Processo Coletivo Transnacional: Extraterritorialidade física ou jurídica 
Revista Eletrônica de Direito Processual - REDP.

Rio de Janeiro. Ano 13. Volume 20. Número 1. Janeiro a Abril de 2019

Periódico Quadrimestral da Pós-Graduação Stricto Sensu em Direito Processual da UERJ

Patrono: José Carlos Barbosa Moreira (in mem.). ISSN 1982-7636. pp. 131-153

www.redp.uerj.br

Antes de adentrar nos debates enfrentados pela União Europeia quanto ao tema da jurisdição na tutela coletiva transnacional, primeiro é importante estabelecer-se neste artigo alguns conceitos centrais.

Um caso será transnacional quando vincular-se a mais de um sistema jurídico nacional $^{2}$, pela existência de um ou mais elementos de estraneidade, seja em razão da nacionalidade ou domicílio das pessoas envolvidas, seja em razão do local em que ocorreu $\mathrm{o}$ ato que fundamenta o pedido, ou mesmo do local do fato (dano) (considerando que o local do ato e do dano podem estar sob diferentes jurisdições). O elemento de estraneidade presente na controvérsia torna necessário verificar a existência de jurisdição para o caso. ${ }^{3}$

Diante disso, no Brasil, o CPC/15 utiliza-se da expressão "dos limites da jurisdição nacional" para tratar, entre os arts.21 e 25, as hipóteses em que o Estado Brasileiro poderá julgar uma demanda com elementos de estraneidade. Trata-se de tema relacionado à jurisdição no plano internacional e não à competência internacional, embora a doutrina já tenha adotado a prática de utilizar o termo "jurisdição" e "competência internacional" indistintamente ${ }^{4}$ o que também será feito ao longo desse artigo.

Sob outra perspectiva, ao tratar das regras comunitárias de competência para litígios com elementos de estraneidade na União Europeia, a exemplo do Regulamento $\mathrm{n}$. 1215/2012 (Bruxelas I), o correto é falar em competência internacional, e não jurisdição, pois esta é organizada e dividida entre Estados soberanos, definindo aqueles que poderão apreciar determinadas controvérsias. ${ }^{5}$

A existência de jurisdição ou competência internacional é questionada diante de casos transnacionais, que podem ser individuais ou possuir uma abrangência maior, quando envolverem grupos de pessoas indeterminadas (podendo, inclusive, tratar-se de

\footnotetext{
${ }^{2}$ BOGGIANO, Antônio. Curso de Derecho Internacional Privado. Derecho de las relaciones privadas internacionales. $2^{\mathrm{a}}$ ed. Buenos Aires: Abeledo-Perrot, 2000, p.16.

${ }^{3}$ TIBURCIO, Carmen. Extensão e Limites da Jurisdição Brasileira: competência internacional e imunidade de jurisdição. Salvador: Juspodivm, 2016, p.22 e 56.

${ }^{4}$ Segundo Carmen Tiburcio, fala-se em jurisdição, enquanto atributo decorrente da soberania do Estado para delimitar quais são as hipóteses que podem ser submetidas a julgamento em seu território. Difere-se da competência internacional, em que a jurisdição se organiza entre Estados soberanos, a exemplo do Regulamento 1215/2012 da União Europeia, que define entre os países membros aqueles que irão apreciar um controvérsia. Entretanto, também a autora, mesmo considerando as distinções terminológicas, utiliza-se das expressões "jurisdição" e "competência internacional" indistintamente. (TIBURCIO, Carmen. Extensão e Limites da Jurisdição Brasileira: competência internacional e imunidade de jurisdição, cit, p.21-24); Nádia de Araújo também utiliza as expressões "jurisdição" e competência internacional" indistintamente. (ARAÚJO, Nádia de. Direito Internacional Privado. Teoria e Prática Brasileira. $1^{\mathrm{a}}$ ed. Porto Alegre: Revolução, eBook,2016.)

${ }^{5}$ TIBURCIO, Carmen. Extensão e Limites da Jurisdição Brasileira: competência internacional e imunidade de jurisdição, cit, p.21-24.
} 
Revista Eletrônica de Direito Processual - REDP.

Rio de Janeiro. Ano 13. Volume 20. Número 1. Janeiro a Abril de 2019

Periódico Quadrimestral da Pós-Graduação Stricto Sensu em Direito Processual da UERJ

Patrono: José Carlos Barbosa Moreira (in mem.). ISSN 1982-7636. pp. 131-153

www.redp.uerj.br

grupo formado por membros estrangeiros, com nacionalidade diversas ${ }^{6}$ ), configurando um dano coletivo a ser solucionado por mecanismos de tutela coletiva (processo coletivo). Neste caso, é preciso adotar um conceito universal de processo coletivo, que se adeque aos mecanismos jurídicos coletivos de diferentes ordenamentos jurídicos (sejam class actions norte-americanas, os litígios agregados, ou modelo brasileiro de processo coletivo) ${ }^{7}$.

Nesse sentido, adota-se aqui, a definição de processo coletivo de Fredie Didier Jr. e Hermes Zaneti $\mathrm{Jr}^{8}{ }^{8}$, para os quais, processo coletivo é aquele em que se postula um direito coletivo lato sensu (situação jurídica coletiva ativa) ou se afirma a existência de uma situação jurídica coletiva passiva. Tal definição se amolda a todos os mecanismos de tutela coletiva, por pautar-se no objeto litigioso e não nas peculiaridades que podem receber diferentes disciplinas em diferentes sistemas jurídicos, à exemplo de legitimidade, competência e regime de coisa julgada. ${ }^{9}$

Feitas essas considerações, o tema tratado neste artigo envolve o processo coletivo transnacional, que é aquele que tem por objeto litigioso uma situação jurídica coletiva passiva ou ativa, envolvendo um ou mais elementos de estraneidade, em razão do local do dano (fato) (danos estão localizados em mais de uma jurisdição), local do ato (embora o dano se limite a um território o ato se produziu em outra jurisdição), ou em razão das pessoas envolvidas (membros do grupo atingido de diferentes domicílios ou nacionalidades ou envolvimento de sociedades estrangeiras, multinacionais).

Esse elemento de estraneidade que caracteriza o processo coletivo transnacional gera o que se pode entender como situações coletivas que extrapolam fronteiras físicas ou jurídicas. Quando se fala em danos plurilocalizados, que afetam a uma diversidade de Estados soberanos tem-se um dano transfronteiriço (extraterritorialidade física), em que o elemento de estraneidade pode ser identificado pelo critério do local do fato. Também a

\footnotetext{
${ }^{6}$ Trata-se do que se denomina foreign plaintiffs ou foreign class members (membros estrangeiros da classe) (MONESTIER, Tanya J.. "Transnational Class Actions and the Illusory Search for Res Judicata", Tulane Law Review, Vol. 86, p. 1-79, 2011; Roger Williams Univ. Legal Studies Paper nº 105, p. 3.)

${ }^{7}$ ZANETI JR., Hermes. "Três Modelos de Processo Coletivo no Direito Comparado: Class actions, Ações Associativas/Litígios Agregados e o 'Processo Coletivo: Modelo Brasileiro." In: Processos Coletivos, v. 5, p. 1, 2014. Disponível em: http://www.processoscoletivos.net/revista-eletronica/63-volume-4-numero-3trimestre-01-07-2014-a-30-09-2014/1460-tres-modelos-de-processo-coletivo-no-direito-comparado-classactions-acoooes-associativas-litigios-agregados-e-o-processo-coletivo-modelo-brasileiro.

Acesso em:02/11/2017.

${ }^{8}$ DIDIER Jr., Fredie; ZANETI Jr., Hermes. "Ações coletivas e o incidente de julgamento de casos repetitivos - espécies de processo coletivo no Direito brasileiro: aproximações e distinções". Revista de Processo. São Paulo: RT, 2016, n. 256, versão digital.

${ }^{9}$ DIDIER Jr., Fredie; ZANETI Jr., Hermes. “Ações coletivas e o incidente de julgamento de casos repetitivos - espécies de processo coletivo no Direito brasileiro: aproximações e distinções", cit, versão digital.
} 
Revista Eletrônica de Direito Processual - REDP.

Rio de Janeiro. Ano 13. Volume 20. Número 1. Janeiro a Abril de 2019

Periódico Quadrimestral da Pós-Graduação Stricto Sensu em Direito Processual da UERJ

Patrono: José Carlos Barbosa Moreira (in mem.). ISSN 1982-7636. pp. 131-153

www.redp.uerj.br

extraterritorialidade física se refere aos casos em que o ato gerador e os danos estejam sob

diferentes territórios nacionais. Por outro lado, a transnacionalidade também está presente em razão das partes envolvidas, ainda que o dano se localize no território de um mesmo Estado, quando, envolver membros afetados com nacionalidade ou domicílios diferentes ou envolver atividades de empresas estrangeiras, multinacionais, filiais (extraterritorialidade da atividade empresarial), caso em que se fala de extraterritorialidade jurídica (danos transnacionais). ${ }^{10}$ Em síntese, todo caso tranfronteiriço é transnacional, mas nem todo caso transnacional será tranfronteiriço.

Diante dessas premissas que se pretende abordar o tema da jurisdição para processos coletivos transnacionais, na União Europeia e no Brasil.

3 União Europeia e Competência internacional para litígios coletivos transnacionais

$\mathrm{Na}$ União Europeia, uma das maiores dificuldades para os litígios coletivos transnacionais tem sido a diversidade de normas processuais nos Estados Membros. A heterogeneidade normativa na regulação dos instrumentos de litígios coletivos e a ausência de previsões uniformes supraestatais, ou seja, comunitárias, têm dificultado o acesso à justiça dos cidadãos. ${ }^{11}$

Nessa perspectiva, para que um litígio coletivo se desenvolva na União Europeia, preliminarmente, haverá que se distinguir: países na União Europeia que não possuem mecanismos de tutela coletiva e países que possuem algum mecanismo; países que adotaram uma regulação geral de tutela coletiva, de países que possuem setores específicos de tutela coletiva, geralmente relacionado às relações de consumo, países que adotam um sistema de opt-out, em que os membros do grupo devem se excluir

\footnotetext{
10 Fala-se em dano transnacional para aqueles em que, apesar do ato e do resultado danoso estarem localizados no território de um mesmo Estado concorre um elemento internacional, não de caráter fático ou material, mas de caráter jurídico ou imaterial. Esse elemento pode ser a tomada de decisão por parte de uma sociedade matriz em um território estrangeiro, a procedência de capital estrangeiro ou tecnologia estrangeira que permitiu as atividades que causaram o dano. (MIQUEL, Mónica Vinaixa. La responsabilidad civil por contaminación transfronteriza derivada de residuos, Universidad de Santiago de Compostela, 2006, p. 374); Nesse sentido, Laura García Álvarez fala em dano que, por sua magnitude e tipologia, são plurilocalizados e afetam diversos Estados ou são danos transnacionais nos quais o elemento internacional é imaterial ou jurídico. A territorialidade dos Estados nacionais se choca com a proteção de um bem de repercussões globais e com a extraterritorialidade das atividades empresariais (GARCÍA ÁLVAREZ, Laura. El acesso al justiça civil em supuestos de daños ambientales causados por grupos transnacionales de sociedades com matrices europeias, Tesis doctoral, Universidad Pablo de Olavide de Sevilla, España, 2015, p. 39).

11 GARCÍA-ALVAREZ, Laura. "Las acciones colectivas en los litigios internacionales por daños ambientales." Revista electrónica de estudios internacionales (REEI), №. 30, 2015. Disponível em: http://www.reei.org/index.php/revista/num30/articulos/acciones-colectivas-litigios-internacionales-danosambientales. Acesso em:02/11/2017, p.11.
} 
Revista Eletrônica de Direito Processual - REDP.

Rio de Janeiro. Ano 13. Volume 20. Número 1. Janeiro a Abril de 2019

Periódico Quadrimestral da Pós-Graduação Stricto Sensu em Direito Processual da UERJ

Patrono: José Carlos Barbosa Moreira (in mem.). ISSN 1982-7636. pp. 131-153

www.redp.uerj.br

expressamente do processo coletivo, de países que adotam um sistema de opt-in, em que os membros devem manifestar-se expressamente em favor de participar. ${ }^{12}$

Em 2013 a Comissão Europeia publicou uma Recomendação ${ }^{13}$ sobre os princípios comuns dos mecanismos de tutela coletiva nos Estados-Membros. Juntamente com a Recomendação, a Comissão publicou uma Comunicação para o Parlamento Europeu ${ }^{14}$, em que elucidou e justificou os princípios comuns enumerados. ${ }^{15}$

A abordagem sobre os litígios coletivos na União Europeia perpassa a análise da Comunicação da Comissão Europeia, da Recomendação de 11 de Junho de 2013 e do Regulamento 1215/2012 (Bruxelas I bis), instrumento regulatório europeu básico para determinação da competência internacional. A partir dessas perspectivas que o presente artigo irá abordar as principais questões sobre competência internacional para processos coletivos transnacionais a nível comunitário europeu.

3.1 O Bruxelas I deve ser aplicado aos litígios coletivos transnacionais na Europa?

Em 11 de junho de 2013, após os debates decorrentes da Consulta Pública realizada pela Comissão Europeia em 2011 e da Comunicação dessa Comissão ao Parlamento Europeu, foi publicada uma Recomendação sobre os princípios comuns aplicáveis aos mecanismos de tutela coletiva na União Europeia. A finalidade dessa Recomendação não é harmonizar os sistemas nacionais, mas configurar um marco que permita às partes prejudicadas obter uma indenização em caso de danos em massa, estabelecendo garantias processuais necessárias para evitar litígios abusivos. ${ }^{16}$

No que se refere aos casos transnacionais a única disposição prevista foi a que admite a legitimidade de entidades representativas estrangeiras ou de grupos estrangeiros,

\footnotetext{
${ }^{12}$ PIÑEIRO, Laura Carballo. "La construcción del mercado interior y el recurso colectivo de consumidores." In: LA ROSA, Fernando Esteban de. La protección del consumidor en dos espacios de integración: Europa y América: Una perspectiva de Derecho internacional, europeo y comparado, 2015, p. 1055-1094.

${ }^{13}$ EUROPA, Recomendação da Comissão de 11 de junho de 2013 sobre os princípios comuns que devem reger os mecanismos de tutela coletiva inibitórios e indemnizatórios dos Estados-Membros aplicáveis às violações de direitos garantidos pelo direito da União. Jornal Oficial da União Europeia (PT). 26/07/2013. Disponível em: http://eur-lex.europa.eu/legal content/PT/TXT/?qid=1509198626388\&uri=CELEX:32013H0396. Acesso em: 02/11/2017

${ }^{14}$ EUROPA, Comunicação da Comissão ao Parlamento Europeu, ao Conselho, ao Comitê Econômico e Social Europeu e ao Comitê das Regiões. Rumo a um quadro jurídico horizontal europeu para a tutela coletiva.Disponível em: http://publications.europa.eu/resource/cellar/d65346fe-eaa6-4655-83d4fc7196637df8.0008.02/DOC_1.Acesso em: 02/11/2017.

15 VOET, Stefaan. "European Collective Redress Developments: A Status Quaestionis". International Journal of Procedural Law, vol 4, 2014/01, p. 97-128, versão digital.

${ }^{16}$ Nesse sentido: VOET, Stefaan. "European Collective Redress Developments: A Status Quaestionis". International Journal of Procedural Law, vol 4, 2014/01, p. 97-128, versão digital. GARCÍA, Ana Montesinos. "Últimas tendencias en la Unión Europea sobre las acciones colectivas de consumo. La posible introducción de fórmulas ADR”, REDUR 12, 2014, págs. 87-112, 2014, p.92.
} 
Revista Eletrônica de Direito Processual - REDP.

Rio de Janeiro. Ano 13. Volume 20. Número 1. Janeiro a Abril de 2019

Periódico Quadrimestral da Pós-Graduação Stricto Sensu em Direito Processual da UERJ

Patrono: José Carlos Barbosa Moreira (in mem.). ISSN 1982-7636. pp. 131-153

www.redp.uerj.br

desde que sejam designadas por algum Estado membro como legitimados para as ações coletivas (ponto 18), não havendo menção à competência judicial internacional para os litígios coletivos transnacionais. ${ }^{17}$

Já na Comissão Europeia ao Parlamento Europeu, foi dedicada uma análise em relação às regras de competência jurisdicional para casos coletivos transfronteiriços, tendo sido levantados diferentes posicionamentos.

Alguns defenderam novas regras para atribuição de competência internacional em litígios de massa, designando-se o local em que reside a maioria das partes que aleguem ter sido prejudicadas. Outros defenderam o critério da competência em função do lugar do domicílio do requerido. Propuseram, ainda, a criação de uma instância especial para as ações coletivas transnacionais junto do Tribunal de Justiça da União Europeia. Mas, dentre os diferentes posicionamentos expostos na Comunicação, o entendimento da Comissão Europeia foi considerar que as normas do Bruxelas I (Regulamento 1215/2012), relativo à competência judiciária, ao reconhecimento e à execução de decisões em matéria civil e comercial, devem ser plenamente exploradas nas ações coletivas transnacionais. ${ }^{18}$

Contudo, na doutrina, tem havido alguma divergência sobre a aplicabilidade do Bruxelas I aos litígios coletivos transnacionais, especialmente porque as hipóteses desse Regulamento 1215/2012 foram previstas para litígios individuais, e não litígios coletivos. Nesse sentido a pergunta que se tem feito por alguns autores que escrevem sobre tutela coletiva na Europa é: Seria necessário criar hipóteses específicas de jurisdição para litígios coletivos transnacionais ou bastaria a interpretação das previsões trazidas pelo Bruxelas I?

Laura Carballo Piñeiro ${ }^{19}$ defende que a interpretação das hipóteses do Bruxelas I já seria suficiente à tutela coletiva transnacional. Para isso, bastaria utilizar-se das previsões de competência internacional em casos extracontratuais, como domicílio do demandado,

\footnotetext{
17 EUROPA, Recomendação da Comissão de 11 de junho de 2013 sobre os princípios comuns que devem reger os mecanismos de tutela coletiva inibitórios e indemnizatórios dos Estados-Membros aplicáveis às violações de direitos garantidos pelo direito da União. Jornal Oficial da União Europeia (PT). 26/07/2013. Disponível em: http://eur-lex.europa.eu/legalcontent/PT/TXT/?qid=1509198626388\&uri=CELEX:32013H0396. Acesso em: 02/11/2017.

${ }^{18}$ EUROPA, Comunicação da Comissão ao Parlamento Europeu, ao Conselho, ao Comitê Econômico e Social Europeu e ao Comitê das Regiões. Rumo a um quadro jurídico horizontal europeu para a tutela coletiva.Disponível em: http://publications.europa.eu/resource/cellar/d65346fe-eaa6-4655-83d4fc7196637df8.0008.02/DOC_1.Acesso em: 02/11/2017.

19 PIÑEIRO, Laura Carballo. "Acciones Colectivas Transfronterizas: Problemas de Derecho Internacional Privado." In: Los servicios em el Derecho Internacional Privado. Jornadas de la ASADIP, Porto Alegre, p.101-149, 2014, p.114-120.
} 
Revista Eletrônica de Direito Processual - REDP.

Rio de Janeiro. Ano 13. Volume 20. Número 1. Janeiro a Abril de 2019

Periódico Quadrimestral da Pós-Graduação Stricto Sensu em Direito Processual da UERJ

Patrono: José Carlos Barbosa Moreira (in mem.). ISSN 1982-7636. pp. 131-153

www.redp.uerj.br

lugar da manifestação ou produção do dano, ou, em casos contratuais, o local do cumprimento da obrigação, por exemplo.

Por outro lado, em posição diversa, Laura García-Alvarez ${ }^{20}$ entende que o Regulamento 1215/2012 (Bruxelas I) não proporciona um mecanismo apto para resolução de demandas coletivas e que, na revisão do Regulamento 44/2001 (antigo Bruxelas), não foi dada devida atenção para incorporação de previsões acerca da competência internacional para litígios coletivos transnacionais.

Além disso, S.I. Strong ${ }^{21}$ aponta que a regra geral de definição da competência internacional no Bruxelas $I$ é o domicílio do demandado. No entanto, considerando a heterogeneidade normativa dos Estados-Membros da União Europeia, pode ocorrer de o local do domicílio do possível demandado sequer possuir mecanismo de tutela coletiva. Para esse autor a melhor solução seria definir o local da jurisdição como aquele em que a maioria dos membros do grupo está domiciliada, prevendo a possibilidade de a ação ser proposta em outra jurisdição, nos casos em que Estado-Membro competente não disponha de tutela coletiva (uma espécie de forum necessitati ${ }^{22}$ ). O autor esperava que, no processo de revisão do Bruxelas, se trouxessem soluções para essa hipótese, mas o Regulamento 1215/2012 não estabeleceu qualquer disposição para esses casos.

Apresentadas diferentes respostas doutrinárias acerca da aplicação do Bruxelas I aos litígios transnacionais, há que se considerar que a resposta da Comissão Europeia foi que o Bruxelas I deve sim ser aplicado à tutela coletiva transnacional. Nessa perspectiva, torna-se relevante abordar quais são as possíveis hipóteses do Regulamento 1215/2012 aplicáveis aos litígios coletivos transnacionais e quais as problemáticas daí resultantes.

\subsection{Bruxelas I e litígios coletivos transnacionais: Hipóteses e discussões}

A competência judicial internacional, na maioria dos países da Europa, é abordada de uma maneira mais rígida, com previsões expressas de hipóteses de competência,

20 GARCÍA-ALVAREZ, Laura. "Las acciones colectivas en los litigios internacionales por daños ambientales", cit, p. 11.

${ }^{21}$ S.I STRONG. "Cross-Border Collective Redress in the European Union: Constitutional Rights in the Face of the Brussels I Regulation", Arizona State Law Journal, Vol. 45, 2013; University of Missouri School of Law Legal Studies Research Paper No. 2012-19, p.02-54, p.45.

${ }^{22}$ Doutrina que se aplica quando um tribunal não tem competência para julgar uma disputa, mas assume jurisdição por considerar que não há outro foro no qual a disputa possa ser julgada ou que o autor possa razoavelmente iniciar o processo. (NWAPI, Chilenye. "Jurisdiction by Necessity and the Regulation of the Transnational Corporate Actor". Utrecht Journal of International and European Law, Vol. 30, n 78, p. 2443, 2014). 
Revista Eletrônica de Direito Processual - REDP.

Rio de Janeiro. Ano 13. Volume 20. Número 1. Janeiro a Abril de 2019

Periódico Quadrimestral da Pós-Graduação Stricto Sensu em Direito Processual da UERJ

Patrono: José Carlos Barbosa Moreira (in mem.). ISSN 1982-7636. pp. 131-153

www.redp.uerj.br

levando-se em consideração o princípio da proximidade e da vinculação razoável do tribunal ao assunto. ${ }^{23}$

As principais jurisdições possíveis para tutela coletiva na União Europeia são o domicílio do demandado (art.4 do Bruxelas I) e o local do dano (art.7.2 do Bruxelas I). ${ }^{24}$

O domicílio do demandado é a regra geral da definição de competência internacional na União Europeia, podendo-se inclusive demandar empresas no local da sede estatutária, da administração central e do centro da atividade principal. Entretanto, em relação às demandas coletivas, já se defende que essa hipótese do Regulamento 1215/2015 não pode ser considerada exclusiva para ações coletivas, porque poderia privilegiar o demandado no processo, que muitas vezes é uma empresa multinacional e se coloca em posição economicamente forte em face dos afetados, que, se estiverem domiciliados em outros países, podem ter que arcar com altos custos para ter analisada a pretensão do grupo. Ademais, existe a possibilidade de o domicílio do demandado não possuir mecanismo de tutela coletiva. ${ }^{25}$

Além do domicílio do demandado, o art.7.2 do Bruxelas I traz a previsão de definição da competência internacional para uma demanda coletiva no local onde ocorreu ou poderá ocorrer o fato danoso (que permite processar por todos os danos no lugar do ato que causou o dano - local do evento gerador do dano). ${ }^{26}$

Sobre o critério do local do dano, há uma problemática europeia em relação aos danos coletivos, especialmente os ambientais. No local de verificação do dano, a competência do juízo recai apenas sobre os danos ocorridos nos limites territoriais do Estado-Membro julgador, enquanto no local do evento gerador do dano, pode-se demandar pela integralidade das consequências. Trata-se da teoria do mosaico desenvolvida no caso Shevill ${ }^{27}{ }^{28}$

\footnotetext{
${ }^{23}$ PIÑEIRO, Laura Carballo. "La construcción del mercado interior y el recurso colectivo de consumidores", cit, p.1070.

${ }^{24}$ GARCÍA-ALVAREZ, Laura. "Las acciones colectivas en los litigios internacionales por daños ambientales", cit, p.11.

${ }^{25}$ Ibidem, p.16.

${ }^{26}$ Idem.

${ }^{27}$ STJCE 7 março 1995, Fiona Shevill, C-68/93.

28 GARCÍA-ALVAREZ, Laura. "Las acciones colectivas en los litigios internacionales por daños ambientales", cit, p.17. Também faz uma abordagem da problemática TIBURCIO, Carmen. Extensão e Limites da Jurisdição Brasileira: competência internacional e imunidade de jurisdição, cit, p.60.
} 
Revista Eletrônica de Direito Processual - REDP.

Rio de Janeiro. Ano 13. Volume 20. Número 1. Janeiro a Abril de 2019

Periódico Quadrimestral da Pós-Graduação Stricto Sensu em Direito Processual da UERJ

Patrono: José Carlos Barbosa Moreira (in mem.). ISSN 1982-7636. pp. 131-153

www.redp.uerj.br

Mas Laura Garcia-Alvarez ${ }^{29}$ menciona que o Tribunal de Justiça da União Europeia já admitiu, em um caso de violações pela Internet, a possibilidade de competência dos tribunais em que apenas parte do dano tenha se verificado sobre o total das reclamações, mesmo que não seja o local da origem do dano. Esse entendimento, para a autora, significou reconhecer que um tribunal nacional possa julgar um caso em que os atos tenham se realizado no estrangeiro e as pessoas afetadas também estejam no estrangeiro.

Diante disso permite-se dois questionamentos: Pode se demandar por todos os danos em um local em que, embora se verifiquem danos, não seja o mais afetado? E, ainda, a necessidade de litigância coletiva pode ser o critério de conexão especial que permite litigar pela totalidade dos danos em outro lugar diferente do local em que foi originado o dano?

Quanto ao primeiro questionamento, considerando a possibilidade de haver grandes dificuldades para localização do local mais afetado pelo dano, Laura Garcia-Alvarez ${ }^{30}$ sustenta que a jurisdição sobre a totalidade dos danos poderá ser exercida no tribunal de qualquer lugar em que se tenha verificado danos, mesmo que não seja o mais afetado, sempre que haja uma conexão razoável para tal e seja previsível ao demandado.

Em relação ao segundo, quando existirem elementos mínimos de conexão, defendese que sociedades de grupos transnacionais sejam demandadas nos países que possuam normas legais e mecanismos de tutela coletiva mais desenvolvidos e eficazes. Essa hipótese pode ser importante para um julgamento final justo, porque, embora haja o alto custo da litigância no estrangeiro, a expectativa de um resultado mais benéfico para o grupo pode ser compensatória. Além disso, pode-se evitar que os danos sofridos fiquem sem reparação. Nesse sentido, países europeus já admitiram essa possibilidade em casos como Akpan vs. Shell Nigeria ${ }^{31}$ e Trafigura ${ }^{32}{ }^{33}$

29 GARCÍA-ALVAREZ, Laura."Las acciones colectivas en los litigios internacionales por daños ambientales",cit, p.17.

${ }^{30}$ Ibidem, cit, p.19.

${ }^{31}$ Nesse caso, ativistas ambientais processaram a Shell, pelo derramamento de petróleo na Nigéria, perante o Tribunal da Holanda, uma vez que a matriz é britânica e holandesa. O Tribunal Holandês julgou o caso, parcialmente favorável, decidindo pela condenação à indenização em relação a uma das acusações.

${ }^{32} \mathrm{O}$ tribunal holandês considerou a multinacional Trafigura culpada de exportar ilegalmente resíduos tóxicos de Amsterdã e ocultar a natureza da carga. Esses resíduos tóxicos eram transportados pela empresa e descarregados na Costa do Marfim, gerando a lesão de milhares de pessoas deste país. A empresa recebeu uma multa de 1 milhão de euros.

33 GARCÍA-ALVAREZ, Laura. "Las acciones colectivas en los litigios internacionales por daños ambientales",cit, p.22-23. 
Revista Eletrônica de Direito Processual - REDP.

Rio de Janeiro. Ano 13. Volume 20. Número 1. Janeiro a Abril de 2019

Periódico Quadrimestral da Pós-Graduação Stricto Sensu em Direito Processual da UERJ

Patrono: José Carlos Barbosa Moreira (in mem.). ISSN 1982-7636. pp. 131-153

www.redp.uerj.br

Entre as jurisdições concorrentes, a busca do país em que haja normas legais e mecanismos de tutela mais avançados, configura o que se denomina forum shopping. Embora a doutrina sempre tenha abordado a busca do sistema jurídico mais favorável sob uma perspectiva negativa, nos litígios coletivos, especialmente, pode significar uma aspiração legítima pela justa reparação do dano. Nesse sentido, nem sempre o forum shopping deve ser considerado fraudulento ${ }^{34}$, podendo configurar, em alguns casos, a busca de acesso efetivo à justiça.

Em essência, a necessidade de litigância coletiva como critério especial de conexão é uma medida de forum necessitatis, porque, diante da impossibilidade de conduzir o processo no foro estrangeiro com jurisdição, o foro demandado, mesmo incompetente irá julgar o caso visando garantir a reparação coletiva do grupo ${ }^{35}$.

Nas propostas de revisão do Bruxelas I, foi expressamente sugerida a inclusão de um artigo que se amoldaria a possibilidade de aplicação do forum necessitatis entre os Estados membros, para casos de tutela coletiva transnacional. ${ }^{36}$ Entretanto, não houve introdução dessa previsão no texto final do Regulamento 1215/2012, o que, no entanto, não impede a sua aplicação, desde que respeitado o critério de conexão razoável.

Apresentados os principais pontos de debates em relação ao Bruxelas I, se observa, que esse instrumento não foi capaz de prever algumas situações decorrentes de litígios coletivos, que são impensadas para litígios individuais. Possivelmente, será necessária uma flexibilização interpretativa, para adequar as regras de competência aos litígios coletivos transnacionais na União Europeia, algo que talvez seja intensificado com o maior desenvolvimento da tutela coletiva comunitária europeia.

\section{Jurisdição brasileira para processos coletivos transnacionais: $O$ que o Brasil}

\section{pode aprender com a União Europeia?}

\footnotetext{
${ }^{34}$ Nesse sentido: FERRARI, Franco. "Forum shopping in the International Commercial Arbitration Context: Setting the Stage". In: FERRARI, Franco. Forum shopping in the international commercial arbitration context. Munich: Sellier European Law Publishers, 2013, p. 1-24.

${ }^{35}$ S.I STRONG. "Cross-Border Collective Redress in the European Union: Constitutional Rights in the Face of the Brussels I Regulation", cit, p.45

36"Where no court of a Member State has jurisdiction under this Regulation, the courts of a Member State may, on an exceptional basis, hear the case if the right to a fair trial or the right to access to justice so requires, in particular: (a) if proceedings cannot reasonably be brought or conducted or would be impossible in a third State with which the dispute is closely connected; or (b) if a judgment given on the claim in a third State would not be entitled to recognition and enforcement in the Member State of the court seised under the law of that State and such recognition and enforcement is necessary to ensure that the rights of the claimant are satisfied;" (S.I STRONG. "Cross-Border Collective Redress in the European Union: Constitutional Rights in the Face of the Brussels I Regulation”, cit, p.44)
} 
Revista Eletrônica de Direito Processual - REDP.

Rio de Janeiro. Ano 13. Volume 20. Número 1. Janeiro a Abril de 2019

Periódico Quadrimestral da Pós-Graduação Stricto Sensu em Direito Processual da UERJ

Patrono: José Carlos Barbosa Moreira (in mem.). ISSN 1982-7636. pp. 131-153

www.redp.uerj.br

A dificuldade em delimitar territorialmente situações jurídicas coletivas pode referir-se a duas dimensões: a) De competência interna, quando a situação jurídica coletiva, embora ultrapasse fronteiras entre Municípios, Estados ou Regiões, está delimitado dentro de um Estado Nacional; b) De competência internacional (jurisdição), quando a situação jurídica coletiva possui elementos de contato com mais de um país, seja pela extraterritorialidade física (danos transfronteiriços) ou pela extraterritorialidade jurídica (danos transnacionais), conforme explicado no início deste artigo.

No Brasil, muito já se desenvolveu sobre o tema da competência interna nas ações coletivas, em face de danos locais, regionais ou nacionais, a partir do estudo das regras do art. $2^{\circ}$ da Lei da Ação Civil Pública e do art. 93 do Código de Defesa do Consumidor e também através do que a doutrina denomina "competência adequada", que é a necessidade de aplicar as regras legais de competência a partir das peculiaridades do caso concreto $^{37}$, considerando fatores como local de obtenção da provas, local da origem do dano, local em que pode ser cumprido o provimento jurisdicional com mais eficiência ${ }^{38}$.

Por outro lado, ainda são poucos os trabalhos ${ }^{39}$ que trouxeram a problemática da competência nas demandas coletivas, não sob o ponto de vista da competência interna, mas sob o ponto de vista da competência internacional (jurisdição), em que a dificuldade de delimitação territorial envolve mais de um Estado. É o tema a ser tratado neste tópico, a partir de um diálogo com as discussões levantadas na abordagem do sistema comunitário europeu de definição da competência internacional.

O estudo da competência internacional na União Europeia em relação aos litígios coletivos transnacionais se fez em duas partes: A primeira para buscar entender se um instrumento de definição de competência pensado para demandas individuais (Bruxelas I) se aplica a casos coletivos internacionais. E a segunda para investigar as hipóteses e problemáticas de aplicação desse instrumento.

\footnotetext{
${ }^{37}$ Fredie Didier Jr e Hermes Zaneti Jr denominam essa adequação entre regras de competência e as peculiaridades do caso de princípio da competência adequada DIDIER JR., Fredie; ZANETI JR., Hermes. Curso de direito processual civil. Processo coletivo. $12^{\mathrm{a}}$ ed. Salvador: JusPodivm, 2018. v. 04., p.140.

${ }^{38}$ RODRIGUES, Marcelo Abelha. Fundamentos da tutela coletiva. Brasília: Gazeta Jurídica, 2017, p.150154

39 É necessário fazer jus a dois relevantes trabalhos que se dedicaram a desenvolver o tema: ZANETI JR., Hermes; BORGES, Orlindo Francisco; CARDOSO, Juliana Provedel. "Ações coletivas transnacionais para tutela de danos ambientais: caso Chevron (STJ, HSE 8.542)". Revista de Direito Ambiental: RDA, São Paulo, v. 21, n. 84, p. 187-213, out./dez. 2016; ZANETI, Graziela Argenta. Jurisdição adequada para os processos coletivos transnacionais. Dissertação da Universidade Federal do Espírito Santo, 2018.
} 
Revista Eletrônica de Direito Processual - REDP.

Rio de Janeiro. Ano 13. Volume 20. Número 1. Janeiro a Abril de 2019

Periódico Quadrimestral da Pós-Graduação Stricto Sensu em Direito Processual da UERJ

Patrono: José Carlos Barbosa Moreira (in mem.). ISSN 1982-7636. pp. 131-153

www.redp.uerj.br

O mesmo esquema será adotado para tratar da extensão da jurisdição brasileira em casos coletivos transnacionais. Primeiramente, buscando investigar a aplicabilidade das regras de jurisdição do Código de Processo Civil aos processos coletivos transnacionais e depois a análise dessas hipóteses e problemáticas daí decorrentes.

\subsection{O CPC/15 deve ser aplicado aos litígios coletivos transacionais submetidos}

\section{à Jurisdição brasileira?}

No Brasil, a competência interna para as ações coletivas está prevista em dois artigos encontrados em legislações que compõem o microssistema do processo coletivo: art. $2^{\circ}$ da Lei da Ação Civil Pública e art.93 do Código de Defesa do Consumidor. O art.2 da LACP condiciona a competência ao "local do dano", enquanto o art.93 do CDC estabelece a competência a partir do âmbito de extensão do dano (dano local, dano regional e dano nacional), não se referindo aos casos de danos transfronteriços ou transnacionais.

Nesse sentido, tomando por base unicamente o microssistema do processo coletivo, poderia se pensar que a única hipótese para definição da jurisdição brasileira seriam as situações em que o dano tenha se produzido no território nacional, estabelecendo-se a competência internacional pelo "local do dano" (art.2 da LACP). Contudo, claramente, o que o art. 2 da LACP prescreve é uma regra de competência interna, não competência internacional (jurisdição).

Diante da ausência de uma regra de jurisdição brasileira para os casos transnacionais no microssistema do processo coletivo, é possível questionar se seria adequado buscar a solução no Código de Processo Civil de 2015, que disciplina, entre os art.21 e 25, os limites da jurisdição nacional.

A aplicabilidade do $\mathrm{CPC} / 15$ às regras de definição da jurisdição brasileira nos litígios coletivos transnacionais pode levar aos mesmos questionamentos que têm sido feitos na União Europeia quanto ao Bruxelas I: Um instrumento cujas regras de competência internacional foram pensadas para litígios individuais pode ser aplicado às demandas coletivas transnacionais? É preciso criar novas hipóteses de jurisdição para litígios coletivos? Ou basta interpretar aquelas já previstas?

Em face desses questionamentos vislumbra-se, principalmente, duas posições: (1) Sustentar que o Brasil necessita criar novas hipóteses de jurisdição especificamente previstas para os casos coletivos transnacionais (em legislação coletiva ou mesmo no 
Revista Eletrônica de Direito Processual - REDP.

Rio de Janeiro. Ano 13. Volume 20. Número 1. Janeiro a Abril de 2019

Periódico Quadrimestral da Pós-Graduação Stricto Sensu em Direito Processual da UERJ

Patrono: José Carlos Barbosa Moreira (in mem.). ISSN 1982-7636. pp. 131-153

www.redp.uerj.br

CPC/15); (2) ou assumir, como já defendido por Carmen Tiburcio ${ }^{40}$, que as regras de jurisdição concorrentes são exemplificativas, e, portanto, poderá haver jurisdição brasileira mesmo que o caso não se enquadre nas hipóteses previstas em lei (ou pode o Brasil não julgar o caso mesmo diante de uma hipótese expressa de jurisdição). Partindo desta posição, bataria interpretar as regras do CPC/15 (art.21 ao 25) para adaptá-las aos casos coletivos transnacionais e admitir a existência de jurisdição brasileira, ainda que não haja previsão, quando, para tutelar uma situação coletiva, a jurisdição se mostrar adequada ou necessária.

Sob essa ótica, defende-se aqui, como fez a Comissão Europeia em relação ao Bruxelas I, que não são necessárias novas previsões legislativas de hipóteses específicas de jurisdição para os litígios coletivos transnacionais, tendo em vista as premissas referidas na segunda posição. Por mais que uma reforma legislativa que incluísse regras de jurisdição para processos coletivos transnacionais pudesse tornar mais claros seus limites e sua extensão, os litígios que não respeitam fronteiras são complexos em si mesmos, de forma que nenhum texto pode suprir todas as suas peculiaridades. Por isso, a melhor solução é a interpretação das regras já previstas no CPC/15 para aplicá-las os casos coletivos transnacionais, admitindo-se a existência de jurisdição brasileira, mesmo que em hipótese não prevista.

Nessa perspectiva, ainda que não tenha havido menção aos litígios coletivos nas regras de extensão e limites da jurisdição brasileira no CPC/15, este deve ser aplicado em diálogo com o processo coletivo, respeitando-se a dimensão coletiva dos direitos tutelados $^{41}$. Trata-se de hipótese de eficácia direta do Código de Processo Civil ao processo coletivo $^{42}$.

4.2 Código de Processo Civil e jurisdição nos litígios coletivos transnacionais: Hipóteses e discussões

Pensando no processo coletivo transnacional, as regras de jurisdição brasileira estão no art.21 do CPC/15, podendo ser fixada se o réu for domiciliado no Brasil (art.21,

\footnotetext{
40 TIBURCIO, Carmen. Extensão e Limites da Jurisdição Brasileira: competência internacional e imunidade de jurisdição, cit, p.104.

${ }^{41}$ ZANETI JR, Hermes. A tutela dos direitos coletivos deve ser preservada no Novo Código de Processo Civil: o modelo combinado de remédios e direitos como garantia de tutela. In: ZANETI JR, Hermes. Repercussões do Novo CPC: Processo Coletivo. Salvador. Juspodivm, 2016.

${ }^{42}$ Sobre a eficácia direta do CPC/15 no processo coletivo, ver: DIDIER Jr., Fredie; ZANETI Jr., Hermes. Curso de direito processual civil. Processo coletivo, cit, p. 61-62; RODRIGUES, Marcelo Abelha. Fundamentos da tutela coletiva, cit, p. 7.
} 
Revista Eletrônica de Direito Processual - REDP.

Rio de Janeiro. Ano 13. Volume 20. Número 1. Janeiro a Abril de 2019

Periódico Quadrimestral da Pós-Graduação Stricto Sensu em Direito Processual da UERJ

Patrono: José Carlos Barbosa Moreira (in mem.). ISSN 1982-7636. pp. 131-153

www.redp.uerj.br

inciso I) ou se o fundamento da ação for fato ocorrido ou ato praticado no Brasil (art.21, inciso III) ${ }^{43}$. Além dessas hipóteses expressamente previstas, defendeu-se no tópico anterior a possibilidade de existir jurisdição brasileira em situações não previstas no rol do CPC, quando, para tutelar uma situação coletiva, a jurisdição se mostrar adequada ou necessária.

A identificação de que a jurisdição brasileira é adequada pode ser feita a partir de critérios como proximidade, acesso à justiça, efetividade, boa-fé. Deve-se evitar a existência de foros exorbitantes, em que não haja vínculos relevantes entre a jurisdição e o litígio (proximidade), garantir o acesso à justiça, preocupando-se, não só com o acesso ao Poder Judiciário, mas também com o processo adequado e efetivo (acesso à justiça e efetividade) e ainda, evitar o abuso do direito de buscar um Judiciário apenas para impedir a defesa do réu (boa-fé). ${ }^{44}$ Critérios como produção probatória, local dos bens do demandado, efetividade do provimento jurisdicional podem ser considerados nessa identificação.

A ponderação das regras de jurisdição brasileira do domicílio do réu e do local do dano, considerando esses princípios como critérios interpretativos, buscam garantir a jurisdição adequada no processo coletivo transnacional.

Como na Europa, o domicílio do réu (art. 21, I, CPC) é a regra geral de jurisdição brasileira, que incidirá mesmo que a hipótese fática envolva situações ocorridas no exterior, bastando que o réu esteja domiciliado no Brasil ${ }^{45}$. Destaque-se dois pontos relevantes: a) havendo réus com domicílios distintos, basta que um deles esteja domiciliado no Brasil para que o Judiciário brasileiro seja competente ${ }^{46}$; e b) considera-se domiciliada no Brasil a pessoa jurídica estrangeira que aqui tiver agência, filial ou sucursal (art.21, parágrafo único).

A regra geral de jurisdição já traz uma discussão em relação aos casos coletivos. Imaginando-se situações que envolvam grupos de pessoas ou situações fáticas distantes do

\footnotetext{
${ }^{43}$ As hipóteses de competência exclusiva do art.23 do CPC/15 (antigo art.89 do CPC/73) são impensáveis para ações coletivas transnacionais. Nesse sentido: "Não há como se justificar a aplicação de ações coletivas transnacionais para questões acerca da situação de imóvel no país e inventário e partilha de bens situados no Brasil, ainda que o autor seja estrangeiro e tenha residido fora do território nacional (art. 89, do CPC (LGL12015\1656) - competência exclusiva), diante da inexistência de uma pretensão coletiva lato sensu para tais hipóteses.”. (ZANETI JR., Hermes; BORGES, Orlindo Francisco; CARDOSO, Juliana Provedel. "Ações coletivas transnacionais para tutela de danos ambientais: caso Chevron (STJ, HSE 8.542)", cit, versão digital. ${ }^{44}$ TIBURCIO, Carmen. Extensão e Limites da Jurisdição Brasileira: competência internacional e imunidade de jurisdição, ob.cit, p.137.

${ }^{45}$ Ibidem, p. 43.

${ }^{46}$ Ibidem, p. 45.
} 
Revista Eletrônica de Direito Processual - REDP.

Rio de Janeiro. Ano 13. Volume 20. Número 1. Janeiro a Abril de 2019

Periódico Quadrimestral da Pós-Graduação Stricto Sensu em Direito Processual da UERJ

Patrono: José Carlos Barbosa Moreira (in mem.). ISSN 1982-7636. pp. 131-153

WWW.redp.uerj.br

Brasil, poderia se afirmar não ser conveniente a jurisdição brasileira, ainda que o réu esteja aqui domiciliado, ao argumento de que as demandas coletivas tutelam situações de grupos que não estão presentes no processo, o que tornaria recomendável a jurisdição mais próxima do grupo/situação jurídica coletiva tutelados. Parece ser com base nessa análise que se discute na União Europeia que a jurisdição nas demandas coletivas seja definida no local em que a maioria dos membros do grupo é domiciliada.

De fato, privilegiar que o Judiciário mais próximo dos afetados julgue a causa é um ponto de partida importante para os processos coletivos transnacionais, mas que não pode afastar a jurisdição do domicílio do réu. Não por uma suposta necessidade de se assegurar o devido processo legal aos requeridos de processos coletivos transnacionais, muitas vezes enormes e poderosas corporações multinacionais, mas pelo ponto de vista da responsabilidade de empresas integrantes de conglomerados multinacionais por atos cometidos por empresas parentes no exterior. Em algumas circunstâncias de grupos afetados em países em desenvolvimento, é preciso buscar a jurisdição no domicílio das matrizes, porque, no país de origem dos membros do grupo, não seria possível receber uma tutela suficiente aos direitos violados, como nos casos Akpan vs. Shell Nigeria e Trafigura, citados no tópico da União Europeia.

Nesse sentido, embora o Brasil geralmente ocupe o papel de local em que empresas estrangeiras exploram suas atividades econômicas, por meio de filiais, subsidiárias, etc, a regra de jurisdição do domicílio do réu pode assegurar a responsabilidade de empresas matrizes brasileiras por atos cometidos por empresas do mesmo conglomerado no exterior. Nada mais natural em um contexto de globalização, em que essas corporações auferem muitos benefícios econômicos pela atividade internacional. Neste ponto, vale mencionar o caso da Construtora Odebrecht em Angola ${ }^{47}$, em que a empresa brasileira foi condenada por atos cometidos por empresas parentes em Angola, pela submissão de trabalhadores à condição análoga a de escravo ${ }^{48}$.

\footnotetext{
${ }^{47}$ Ação Civil Pública n. 10230-31.2014.5.15.0079 do Ministério Público do Trabalho.

48:"Neste caso, o Ministério Público do Trabalho propôs Ação Civil Pública 517 perante a $2^{\circ}$ Vara do Trabalho em Araraquara, pleiteando, em síntese, a condenação da Construtora Norberto Odebrecht S/A., da Olex Importação e Exportação S.A. e da Odebrecht Agroindustrial S.A. (antes denominada ETH Bioenergia), em obrigações de fazer e de não fazer, bem como indenizações por danos morais coletivos por contratação irregular (arregimentar trabalhadores de forma irregular com aliciamento, merchandage e tráfico internacional de seres humanos) e por manter trabalhadores em Angola, em desrespeito a direitos trabalhistas e com cerceamento da liberdade de ir e vir, mediante violência (redução à condição análoga à de escravo), bem como pelo beneficiamento irregular de financiamento do BNDES para aplicação em obras em Angola. (ZANETI, Graziela Argenta. Jurisdição adequada para os processos coletivos transnacionais, cit, p.151)
} 
Revista Eletrônica de Direito Processual - REDP.

Rio de Janeiro. Ano 13. Volume 20. Número 1. Janeiro a Abril de 2019

Periódico Quadrimestral da Pós-Graduação Stricto Sensu em Direito Processual da UERJ

Patrono: José Carlos Barbosa Moreira (in mem.). ISSN 1982-7636. pp. 131-153

www.redp.uerj.br

Além do domicílio do réu, o Código de Processo Civil estabelece a jurisdição

brasileira nos casos em que o fato ou o ato praticado ocorreu no Brasil (art.21, inciso III).

Diferentemente do Bruxelas I (art. 7.2), o CPC não menciona o local onde "poderá ocorrer o fato danoso". Essa lacuna já revela a necessidade de considerar uma hipótese de jurisdição brasileira não prevista expressamente: se o Brasil for o local em que poderá ocorrer o dano, ainda que o ato não tenha sido aqui praticado.

Imaginando, por exemplo que uma empresa estrangeira, que não possui domicílio no Brasil, explore suas atividades em um país de fronteira com o território brasileiro. Essas atividades geram um risco potencial de danos ambientais que podem atingir o Brasil, mas ainda não foram verificados. No país de fronteira em que as atividades se desenvolvem, não há mecanismos de tutela coletiva, nem legislação de proteção ambiental. Poderia ser ajuizada uma ação coletiva preventiva do dano no Brasil? O réu não é domiciliado em território brasileiro, o ato não se originou aqui e ainda não há dano. Considerando que as hipóteses do CPC/15 não são taxativas, afirma-se neste artigo que sim.

Esse caso hipotético pode levar ainda a uma outra questão, discutida na União Europeia: Verificados os danos transfronteiriços, o Judiciário brasileiro poderá apreciar a totalidade dos danos, nas situações em que apenas parte dos danos tenha se verificado no Brasil $^{49}$ ?

A premissa geral do modelo comunitário europeu é que, no local de verificação do dano, a competência do juízo recai apenas sobre os danos ocorridos nos limites territoriais do Estado-Membro julgador, enquanto no local do evento gerador do dano (ato), pode-se demandar pela integralidade das consequências. No Brasil, já se defende uma interpretação ampla do art. 21, inciso III, para admitir que o Judiciário Brasileiro aprecie a totalidade dos danos, ainda que parte deles tenha ocorrido do exterior ${ }^{50}$, e ainda que a menor parte tenha ocorrido no Brasil.

\footnotetext{
${ }^{49}$ Nesse sentido, veja esse exemplo: imaginemos um dano ambiental ocorrido na fronteira do Uruguai e Brasil. Nosso ordenamento jurídico prevê tutela condenatória dos direitos difusos; entretanto, no direito uruguaio, não há previsão de tutela condenatória in pecúnia. Assim, parcela do dano ficará sem reparação, caso não existam mecanismos de cooperação judicial e reconhecimento das decisões brasileiras pelo Estado Uruguaio capazes de tornarem efetiva a tutela integral e erga omnes do direito ambiental, que é, em essência, indivisível, pois trata-se de um só meio ambiente, de um só ecossistema. (MOSCHEN, Valesca Raizer Borges; ZANETI, Graziela A.. "Processo Internacional Transfronteiriço: os litígios que não respeitam fronteiras - da soberania à tutela dos direitos". In: Bruno Manoel Viana; Valesca Raizer Borges Morchen; Valter Moura do Carmo. (Org). Direito Internacional II. $1^{\text {a }}$ ed. Florianópolis: COMPEDI, 2016, v. 1.)

${ }^{50}$ TIBURCIO, Carmen. Extensão e Limites da Jurisdição Brasileira: competência internacional e imunidade de jurisdição, ob.cit,p.61
} 
Revista Eletrônica de Direito Processual - REDP.

Rio de Janeiro. Ano 13. Volume 20. Número 1. Janeiro a Abril de 2019

Periódico Quadrimestral da Pós-Graduação Stricto Sensu em Direito Processual da UERJ

Patrono: José Carlos Barbosa Moreira (in mem.). ISSN 1982-7636. pp. 131-153

www.redp.uerj.br

Note-se que, nesses casos em que o ato e os danos são produzidos em diferentes territórios, os mecanismos de cooperação internacional e de homologação de sentença estrangeira mostram-se fundamentais. No Brasil eles estão previstos nos arts. 26 a 41 e arts. 960 a 965 do CPC, além de algumas previsões em tratados internacionais.

Acrescente-se uma última discussão já travada no contexto europeu e aplicável ao contexto da América do Sul: Há possibilidade de exercício da jurisdição com base no forum necessitatis, quando no foro concorrente não houver tutela coletiva ou quando, mesmo havendo, exista outro local em que as normas e mecanismos legais e coletivos sejam mais desenvolvidos e eficazes? Isto é, a necessidade de litigancia coletiva e de mecanismos protetivos podem justificar a jurisdição de outro território sobre a totalidade dos danos?

Defende-se neste artigo, como já se tem defendido em relação à União Europeia, que o Brasil deve adotar o forum necessitatis para, havendo mínimos elementos de conexão, admitir sua jurisdição diante da impossibilidade ou dificuldade de se conduzir o processo em outro foro, pela ausência de mecanismos coletivos ou pela ausência de normas legais de proteção para o caso. Trata-se de decorrência do princípio constitucional do acesso à justiça, que permite ao Judiciário brasileiro, mesmo fora das regras expressas do art.21 do CPC/15, resolver uma demanda coletiva transnacional, quando no país de foro concorrente não houver tutela coletiva ou quando os mecanismos não se mostrarem suficientes para garantir a justiça do caso, desde que ponderadas a possibilidade de entrega efetiva do resultado (efetividade) e que não importe em impossibilidade de defesa do réu (boa-fé).

A adoção do mecanismo do forum necessitatis, nesses casos, pode contribuir para que as vítimas de danos coletivos que não possuem todos os recursos judiciais no local mais próximo dos fatos não fiquem desamparadas. ${ }^{51}$ Claro que, no contexto comunitário europeu, essa questão é mais relevante pela própria intensidade do fenômeno da globalização. Mas na América do Sul, o debate ganha importância pelo fato de que poucos países possuem um modelo de processo coletivo ${ }^{52}$, como o Brasil possui.

São temas que, a exemplo da União Europeia, ainda precisam ser amadurecidos.

\footnotetext{
${ }^{51}$ MARULLO, Maria Chiara, "Access to Justice and Forum Necessitatis in Transnational Human Rights Litigation", HURI-AGE, Consolider-Ingenio 2010, p. 01-28, 2015, p.25

${ }^{52} \mathrm{Na}$ América do Sul apenas o Brasil, a Argentina, o Uruguai, o Peru e o Chile detêm um modelo processual para a tutela de ações coletivas. (GRINOVER, Ada Pellegrini; WATANEBE, Kazuo; MULLENIX, Linda. Os processos coletivos nos países de Civil Law e de Common Law. 2. ed. São Paulo: Ed. RT, 2014.)
} 


\section{Considerações finais}

O processo foi por muito tempo pensado para relações jurídicas individuais e delimitadas territorialmente. Mas no contexto da contemporaneidade, com o advento da globalização e intensificação das atividades das empresas na economia global, as situações que desafiam o processo não são mais somente aquelas individuais e delimitadas. Fala-se agora em processos coletivos transnacionais.

As regras de jurisdição, sempre pensadas sob a ótica dos casos individuais, para proteção do réu, agora se colocam em face de litígios coletivos extraterritoriais, em que o réu geralmente é uma grande empresa, às vezes multinacional, e os afetados pessoas vulneráveis diante dessas empresas. Como repensar as regras de jurisdição para atender esses novos litígios?

Esse foi o problema central enfrentado neste artigo, o que se fez sob o ponto de vista do contexto europeu, que embora ainda esteja se desenvolvendo em termos de processo coletivo, já se preocupa em como adaptar as regras de jurisdição aos casos coletivos transacionais. No âmbito das normas comunitárias, isso tem sido feito a partir do Regulamento 1215/2012 para entender como preencher as lacunas de um instrumento pensado para demandas individuais e criar critérios interpretativos que permitam pensar normas de jurisdição voltadas para reparação do dano e tutela do grupo afetado.

E o que o Brasil pode aprender com o que já tem sido discutido da União Europeia?

Em síntese, a possibilidade de adaptar as regras de jurisdição do Código de Processo Civil de 2015, também pensadas para demandas individuais, para as demandas coletivas. Entender as regras do art. 21 do CPC como não taxativas, permitindo-se flexibilização interpretativa das hipóteses de jurisdição, a partir do caso concreto, com vistas à tutela do dano e do grupo. Nesse sentido, no Brasil, a preocupação já existente com a competência interna deve existir também para competência internacional. A ideia de competência adequada nas ações coletivas deve abranger a competência interna e a competência internacional.

\section{REFERÊNCIAS BIBLIOGRÁFICAS:}

ARAÚJO, Nádia de. Direito Internacional Privado. Teoria e Prática Brasileira. $1^{\mathrm{a}}$ ed. Porto Alegre: Revolução, eBook, 2016. 
Revista Eletrônica de Direito Processual - REDP.

Rio de Janeiro. Ano 13. Volume 20. Número 1. Janeiro a Abril de 2019

Periódico Quadrimestral da Pós-Graduação Stricto Sensu em Direito Processual da UERJ

Patrono: José Carlos Barbosa Moreira (in mem.). ISSN 1982-7636. pp. 131-153

www.redp.uerj.br

BOGGIANO, Antônio. Curso de Derecho Internacional Privado. Derecho de las relaciones privadas internacionales. $2^{\mathrm{a}}$ ed. Buenos Aires: Abeledo-Perrot, 2000.

DIDIER Jr., Fredie; ZANETI Jr., Hermes. “Ações coletivas e o incidente de julgamento de casos repetitivos - espécies de processo coletivo no Direito brasileiro: aproximações e distinções.” Revista de Processo. São Paulo: RT, 2016, n. 256.

DIDIER Jr., Fredie; ZANETI Jr., Hermes. Curso de direito processual civil. Processo coletivo. 12a ed. Salvador: JusPodivm, 2018. v. 04.

EUROPA, Recomendação da Comissão de 11 de junho de 2013 sobre os princípios comuns que devem reger os mecanismos de tutela coletiva inibitórios e indemnizatórios dos Estados-Membros aplicáveis às violações de direitos garantidos pelo direito da União. Jornal Oficial da União Europeia (PT). 26/07/2013. Disponível em: http://eur-lex.europa.eu/legalcontent/PT/TXT/?qid=1509198626388\&uri=CELEX:32013H0396. Acesso em: 02/11/2017.

, Comunicação da Comissão ao Parlamento Europeu, ao Conselho, ao Comitê

Econômico e Social Europeu e ao Comitê das Regiões. Rumo a um quadro jurídico horizontal europeu para a tutela coletiva. Disponível em:

http://publications.europa.eu/resource/cellar/d65346fe-eaa6-4655

83d4fc7196637df8.0008.0/DOC_1.DOC_1. Acesso em: 02/11/2017.

FERRARI, Franco. "Forum shopping in the International Commercial Arbitration Context: Setting the Stage". In: FERRARI, Franco. Forum shopping in the international commercial arbitration context. Munich: Sellier European Law Publishers, 2013, p. $1-24$.

GARCÍA, Ana Montesinos. "Últimas tendencias en la Unión Europea sobre las acciones colectivas de consumo. La posible introducción de fórmulas ADR", REDUR 12, págs. 87-112, 2014.

GARCÍA-ALVAREZ, Laura. "Las acciones colectivas en los litigios internacionales por daños ambientales. ". Revista electrónica de estudios internacionales (REEI), $N^{o}$. 30, 2015 , p.11. Disponível em: http://www.reei.org/index.php/revista/num30/articulos/acciones-colectivas-litigiosinternacionales-danos-ambientales. Acesso em:02/11/2017. 
Revista Eletrônica de Direito Processual - REDP.

Rio de Janeiro. Ano 13. Volume 20. Número 1. Janeiro a Abril de 2019

Periódico Quadrimestral da Pós-Graduação Stricto Sensu em Direito Processual da UERJ

Patrono: José Carlos Barbosa Moreira (in mem.). ISSN 1982-7636. pp. 131-153

www.redp.uerj.br

El acesso al justiça civil em supuestos de daños ambientales causados por grupos

transnacionales de sociedades com matrices europeias, Tesis doctoral, Universidade

Pablo de Olavide de Sevilla, España, 2015.

GRINOVER, Ada Pellegrini; WATANEBE, Kazuo; MULLENIX, Linda. Os processos coletivos nos países de Civil Law e de Common Law. 2. ed. São Paulo: Ed. RT, 2014

MARULLO, Maria Chiara, "Access to Justice and Forum Necessitatis in Transnational Human Rights Litigation”. HURI-AGE, Consolider-Ingenio 2010, p. 01-28, 2015.

MIQUEL, Mónica Vinaixa. La responsabilidad civil por contaminación transfronteriza derivada de residuos, Universidad de Santiago de Compostela, 2006.

MONESTIER, Tanya J.. "Transnational Class Actions and the Illusory Search for Res Judicata", Tulane Law Review, Vol. 86, p.1-79, 2011; Roger Williams Univ. Legal Studies Paper $\mathrm{n}^{\mathrm{o}} 105$.

MOSCHEN, Valesca Raizer Borges; ZANETI, Graziela A.. "Processo Internacional Transfronteiriço: os litígios que não respeitam fronteiras - da soberania à tutela dos direitos”. In: Bruno Manoel Viana; Valesca Raizer Borges Morchen; Valter Moura do Carmo. (Org). Direito Internacional II. $1^{\text {a }}$ ed. Florianópolis: COMPEDI, 2016, v. 1.

NWAPI, Chilenye. "Jurisdiction by Necessity and the Regulation of the Transnational Corporate Actor". Utrecht Journal of International and European Law, Vol. 30, $\mathrm{n}^{\circ}$ 78, p. 24-43, 2014.

PIÑEIRO, Laura Carballo. “Acciones Colectivas Transfronterizas: Problemas de Derecho Internacional Privado." In: Los servicios em el Derecho Internacional Privado. Jornadas de la ASADIP. Porto AAlegre, p. 101-149, 2014.

. "La construcción del mercado interior y el recurso colectivo de consumidores." In:

LA ROSA, Fernando Esteban de. La protección del consumidor en dos espacios de integración: Europa y América: Una perspectiva de Derecho internacional, europeo y comparado, 2015, p. 1055-1094.

RODRIGUES, Marcelo Abelha. Fundamentos da tutela coletiva. Brasília: Gazeta Jurídica, 2017.

S.I STRONG. "Cross-Border Collective Redress in the European Union: Constitutional Rights in the Face of the Brussels I Regulation." Arizona State Law Journal, Vol. 45, 2013; University of Missouri School of Law Legal Studies Research Paper No. 201219, p.02-54, 2013. 
Revista Eletrônica de Direito Processual - REDP.

Rio de Janeiro. Ano 13. Volume 20. Número 1. Janeiro a Abril de 2019

Periódico Quadrimestral da Pós-Graduação Stricto Sensu em Direito Processual da UERJ

Patrono: José Carlos Barbosa Moreira (in mem.). ISSN 1982-7636. pp. 131-153

www.redp.uerj.br

TIBURCIO, Carmen. Extensão e Limites da Jurisdição Brasileira: competência internacional e imunidade de jurisdição. Salvador: Juspodivm, 2016.

VOET, Stefaan. "European Collective Redress Developments: A Status Quaestionis". International Journal of Procedural Law, vol 4, 2014/01, p. 97-128.

ZANETI, Graziela Argenta. Jurisdição adequada para os processos coletivos transnacionais. Dissertação da Universidade Federal do Espírito Santo, 2018.

ZANETI JR., Hermes. "Três Modelos de Processo Coletivo no Direito Comparado: Class actions, Ações Associativas/Litígios Agregados e o 'Processo Coletivo: Modelo Brasileiro." In: Processos Coletivos, v. 5, p. $1, \quad 2014$. (http://www.processoscoletivos.net/revista-eletronica/63-volume-4-numero-3trimestre-01-07-2014-a-30-09-2014/1460-tres-modelos-de-processo-coletivo-nodireito-comparado-class-actions-acoooes-associativas-litigios-agregados-e-oprocesso-coletivo-modelo-brasileiro).

A tutela dos direitos coletivos deve ser preservada no Novo Código de Processo Civil: o modelo combinado de remédios e direitos como garantia de tutela. In: ZANETI JR., Hermes. Repercussões do Novo CPC: Processo Coletivo. Salvador. Juspodivm, 2016.

ZANETI JR., Hermes; BORGES, Orlindo Francisco; CARDOSO, Juliana Provedel. "Ações coletivas transnacionais para tutela de danos ambientais: caso Chevron (STJ, HSE 8.542)”. Revista de Direito Ambiental: RDA, São Paulo, v. 21, n. 84, p. 187213, out./dez. 2016 